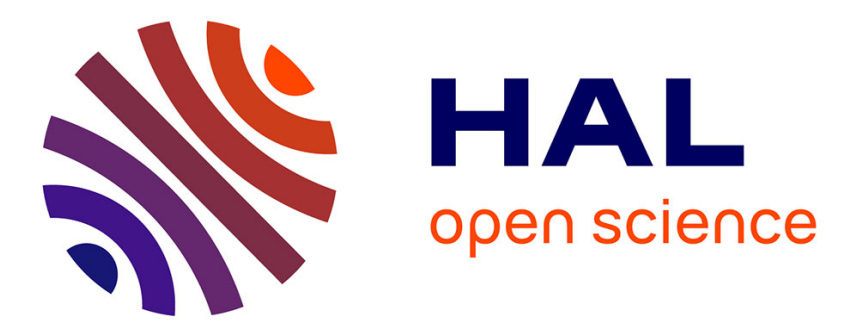

\title{
Piezoelectric tantalum pentoxide studied for optical tunable applications
}

\author{
Rémy Parmentier, Fabien Lemarchand, Michel Cathelinaud, Michel Lequime, \\ Claude Amra, Stéphane Labat, S. Bozzo, Franck Bocquet, Ahmed Charaï, \\ Olivier Thomas, et al.
}

\section{To cite this version:}

Rémy Parmentier, Fabien Lemarchand, Michel Cathelinaud, Michel Lequime, Claude Amra, et al.. Piezoelectric tantalum pentoxide studied for optical tunable applications. Applied optics, 2002, 41 (16), pp.3270-3276. 10.1364/AO.41.003270 . hal-01324143

\section{HAL Id: hal-01324143 \\ https://hal.science/hal-01324143}

Submitted on 18 Dec 2018

HAL is a multi-disciplinary open access archive for the deposit and dissemination of scientific research documents, whether they are published or not. The documents may come from teaching and research institutions in France or abroad, or from public or private research centers.
L'archive ouverte pluridisciplinaire HAL, est destinée au dépôt et à la diffusion de documents scientifiques de niveau recherche, publiés ou non, émanant des établissements d'enseignement et de recherche français ou étrangers, des laboratoires publics ou privés. 


\title{
Piezoelectric tantalum pentoxide studied for optical tunable applications
}

\author{
Rémy Parmentier, Fabien Lemarchand, Michel Cathelinaud, Michel Lequime, \\ Claude Amra, Stéphane Labat, Stéphanie Bozzo, Franck Bocquet, Ahmed Charaï, \\ Olivier Thomas, and Christian Dominici
}

\begin{abstract}
Piezoelectric transparent thin films are of great interest for use in tunable filters. We present experi-mental results on Ta $\mathrm{O}_{5}$ single layers coated on fused-silica substrates with an electron-beam deposition process. Above $450{ }^{\circ} \mathrm{C}$, coatings change from an amorphous to a polycrystallized structure. When this structure shows a preferred orientation matching the piezoelectric tensor of the Ta $\mathrm{O}_{5} \mathrm{crystal}_{\mathrm{c}}$ and the external electric field, variation in the piezoelectric layer thickness is expected. We detail experimental results in terms of optical (spectrophotometric and scattering measurements) and nonoptical character-izations (x-ray diffraction and scanning electron microscopy). Then the resultant thickness variation under oscillating applied voltage is measured with an extrinsic Fabry-Perot interferometer setup.
\end{abstract}

\section{Introduction}

The technique of dense wavelength division multiplexing has dramatically increased the bandwidth of optical fiber transmissions. Multiplexer-demultiplexer devices separate and select different wavelengths that correspond to different required channels. Narrowbandpass functions can be achieved by thin-film filters. Thus each multiplexer-demultiplexer device contains several thin-film filters centered on each transmitted wavelength. The use of tunable narrow-bandpass filters would reduce the number of required thin-film filters within a device and would increase network

R. Parmentier (remy.parmentier@fresnel.fr), F. Lemarchand, M. Cathelinaud, M. Lequime, and C. Amra are with the Institut Fresnel, Unité Mixte de Recherche, Centre National de la Recherche Scientifique 6133, École Nationale Supérieure de Physique de Marseille, Domaine Universitaire de Saint Jérôme, 13397 Marseille, France. S. Labat, S. Bozzo, F. Bocquet, A. Charaï, and O. Thomas are with the Laboratoire Thermodynamique, propriétés Électriques, Contraintes et Structure aux Echelles Nanométriques, Unité Mixte de Recherche, Centre National de la Recherche Scientifique 6122, Domaine Universitaire de Saint Jérôme. C. Dominici is with and A. Charaï is also with Centre pluridisciplinaire de Microscopie et Micro-analyse, Domaine Universitaire de Saint Jérôme. flexibility. Our purpose is to study piezoelectric active layers with variable optical thicknesses.

As described in another paper, ${ }^{1}$ the insertion of one or more piezoelectric layers as spacer layers in a Fabry-Perot cavitylike narrow-bandpass filter permits the shift of the center wavelength by changing the optical thickness. Piezoelectricity is the change of thickness under an applied electric field and is also used to describe the converse effect: the appearance of electrical charges on opposite sides of a solid under mechanical stress. The third-order piezoelectric tensor $d$ (given in picometers per volt) describes mechanical strain as a function of an applied electric field through Eq (1):

$$
\Delta t_{j} / t_{j}=d_{i j} E_{i},
$$

where $t_{j}$ is the crystal thickness along the $j$ axis and $E_{i}$ is the applied electric field in the $i$ direction.

Piezoelectric activity relies mainly on the crystalline structure of the material. That is to say, amorphouslike layers do not exhibit any piezoelectric response. If we analyze in greater depth and list the different possible crystal classes, only nonsymmetrical crystals are piezoelectric. ${ }^{2}$ Nonzero values of the piezoelectric $d$ tensor determine strain directions.

As far as polycrystalline layers are concerned, the resulting effect is the vectorial sum of all the piezo effects induced by microcrystallites. This is the reason why an overall orientation in agreement with the 

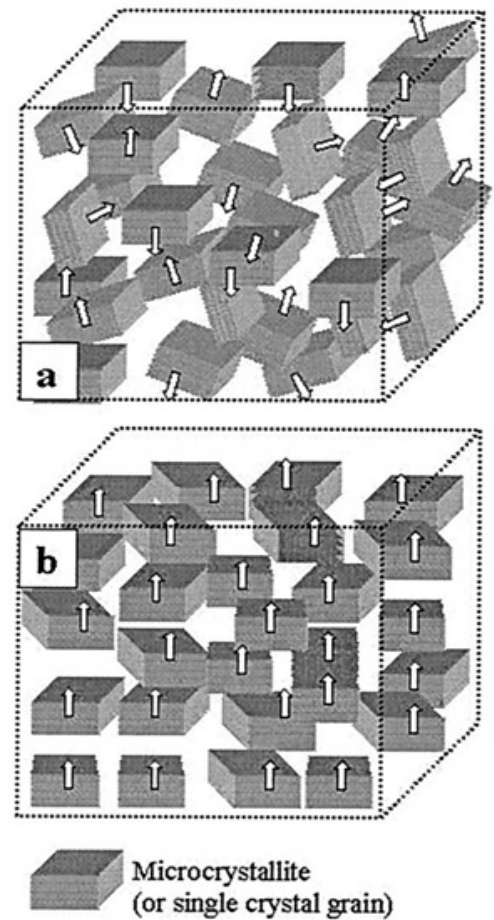

Principal direction of piezoelectric

U) displacement for the crystallite

Fig. 1. (a) Schematic drawing of a randomly oriented crystallite structure and (b) an organized structure with a preferred orientation in the vertical direction If the piezoelectric tensor matches the vertical axis and the electric field direction, a piezoelectric displacement equivalent to the single-crystal structure displacement can occur in the vertical direction.

piezoelectric tensor and the direction of the applied electric field is required. Figure 1 shows a schematic representation of the piezoelectric effect for different microcrystallite organizations. The crystallites of Fig. 1 (a) are randomly oriented. No overall piezoelectric effect can be expected even if each crystallite shows piezoelectricity. In contrast, all the crystallites of Fig. 1 (b) have the same orientation in the vertical direction, although in the horizontal plane crystallites do not present a preferred orientation. In this case, if the vertical direction fits the piezoelectric tensor $d$ and the applied electric field direction, one can expect the same piezoelectric displacement as for a single-crystal growth. For a partially organized growth, the expected piezoelectric effect is, of course, in between and depends on the ratio of well-oriented grains to all grains. ${ }^{3}$

\section{Choice of Dielectric Material}

Dielectric bulky materials with a piezoelectric effect higher than $100 \mathrm{pm} / \mathrm{V}$ and that are absorption free in the optical telecommunications domain include Ba$\mathrm{TiO}_{3}$ and $\mathrm{Ta}_{2} \mathrm{O}_{5}$. One major drawback of the first one is that it exhibits a considerable electro-optic effect $(1640 \mathrm{pm} / \mathrm{V})^{4}$, therefore it is strongly polarization dependent. In contrast, $\mathrm{Ta}_{2} \mathrm{O}_{5}$ is an excellent candidate if one refers to optical properties: large transparency domain, low scattering, and high mechanical and chemical resistance, ${ }^{5,6}$ at least for amorphous layers widely used for thin-film applications. The most stable form of crystallized $\mathrm{Ta}_{2} \mathrm{O}_{5}$ below $1360{ }^{\circ} \mathrm{C}^{7}$ belongs to the orthorhombic class, and values of the piezoelectric tensor elements vary from zero to $200 \mathrm{pm} / \mathrm{V}$ for $d_{33}$ where a displacement along the third axis is expected when an electric field is applied parallel to this axis.

As mentioned above, the expected piezoelectric effect for crystallized $\mathrm{Ta}_{2} \mathrm{O}_{5}$ thin films depends on microcrystallite orientations and is, of course, lower than bulky values. Note that we chose to use amorphous substrates (fused silica) and that we do not use the substrate crystalline lattice replication to help a single crystalline growth as occurs in epitaxy. This choice is justified because, as mentioned previously, our final goal is to deposit active layers within an optical thin-film stack, and we must not control the growth with the substrate. The underlying layer will be either amorphous or crystalline with a noncontrolled orientation. Parameters able to influence the degree of organization of grains are therefore only thin-film deposition parameters (deposition rate, oxygen flow, substrate temperature, and annealing temperature).

\section{3. $\mathrm{Ta}_{\mathbf{2}} \mathrm{O}_{\mathbf{5}}$ Thin-Film Deposition}

The deposition process used is electron-beam deposition or conventional reactive evaporation, ${ }^{8}$ with a deposition temperature variable from ambient temperature to as high as $650{ }^{\circ} \mathrm{C}$. We use a Balzers BAK600 evaporation chamber to deposit $\mathrm{Ta}_{2} \mathrm{O}_{5}$ single layers on fused-silica substrates. Other processes suitable for piezoelectric layer deposition include pulsed laser deposition ${ }^{9,10}$ or radio-frequency sputtering. ${ }^{7,11}$ The deposition rate is controlled by a quartzcrystal measurement unit, and the optical thickness of the reference substrate is controlled by an optical monitoring system at a wavelength of $600 \mathrm{~nm}$ (see Fig. 2).

Both substrates are heated on the front sides with halogen lamps. On the rear side, one substrate is heated at high temperature with a resistive substrate heater. Affordable temperatures range from ambient to as high as $950{ }^{\circ} \mathrm{C}$, and a closed-loop regulation controls the resistive heater's temperature via a K-type thermocouple. Calibration measurements have been performed to monitor the temperature on the deposition side of the substrate. The maximum reachable temperature is approximately $650{ }^{\circ} \mathrm{C}$ on the front side of a 2-mm-thick fused-silica substrate. Oxygen partial pressure in the chamber is also controlled. Material used for the evaporating process is Merck tantalum pentoxide tablets. Key parameters for optical and piezoelectric properties that we can act on are the deposition rate, $\mathrm{O}_{2}$ flow, and substrate temperature. For all layers described in this paper, $\mathrm{O}_{2}$ partial pressure is approximately $2 \times 10^{-4} \mathrm{mbar}$, which ensures a good stoichiometry and then good optical properties. 


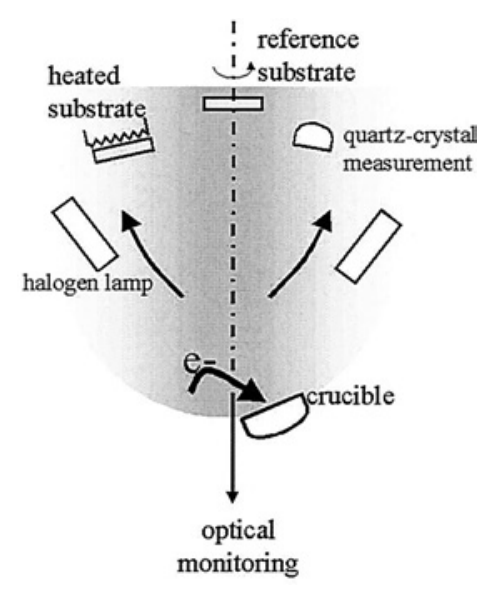

Fig. 2. Evaporation chamber that uses the electron-beam deposition process. An optical monitoring and a quartz crystal measurement is performed on the reference substrate. The temperature of the heated substrate can reach $950{ }^{\circ} \mathrm{C}$ on the rear side.

\section{Temperature Effect on $\mathrm{Ta}_{2} \mathrm{O}_{5}$ Optical Properties}

In accordance with the model of Movchan and Demchishin, ${ }^{12}$ the microstructure of the film layer depends on the substrate temperature $T$ during the deposition process and $T_{m}$, the melting point of tantalum pentoxide $\left(T_{m}=1880^{\circ} \mathrm{C}\right)$. The higher the substrate temperature is, the more energy adatoms have and the more mobility they have to re-arrange themselves in a stable crystalline form. We study here the influence of the film structure on the optical refractive index and scattering losses.

We consider three $\mathrm{Ta}_{2} \mathrm{O}_{5}$ samples coated on fused silica, which are all $t=375 \mathrm{~nm}$ thick. The first one (S1) is coated at a $300{ }^{\circ} \mathrm{C}$ substrate temperature. The second one (S2) is coated at a $470{ }^{\circ} \mathrm{C}$ substrate temperature in the evaporation chamber, thanks to the resistive substrate heater. After characterizations, this sample is annealed at $650{ }^{\circ} \mathrm{C}$ for $4 \mathrm{~h}$ (S3).

At a deposition temperature of $300^{\circ} \mathrm{C}$, the film is totally amorphous. S2 is partially crystallized, and S3's crystallinity is improved by the annealing process. From reflectance and transmittance measurements, we deduce the refractive index $N$ as a function of wavelength. ${ }^{13}$ In the visible range, the imaginary part of the refractive index is lower than $10^{-4}$. On Fig. 3 we have plotted deduced refractive indices $N$ as a function of wavelength for S1, S2, and S3 in the $0.4-0.9 \mu \mathrm{m}$ range. The major effect of an increasing temperature is the raising of the refractive index of the layers from $N=2.06$ to $N=2.24$ at $\lambda=0.6 \mu \mathrm{m}$.

We deduce from light-scattering measurements that optical losses of S2 and S3 are essentially due to the light scattered by crystallites. The size of the grains, which will be discussed in Section 5, influences this amount of scattered light. Scattering properties are investigated at normal incidence at a wavelength of $633 \mathrm{~nm}$ from $4^{\circ}$ to $80^{\circ}$ with an experimental setup described in Ref. 14. Results are plotted on Fig. 4. The general level of scattering increases with temperature, as the crystallization of

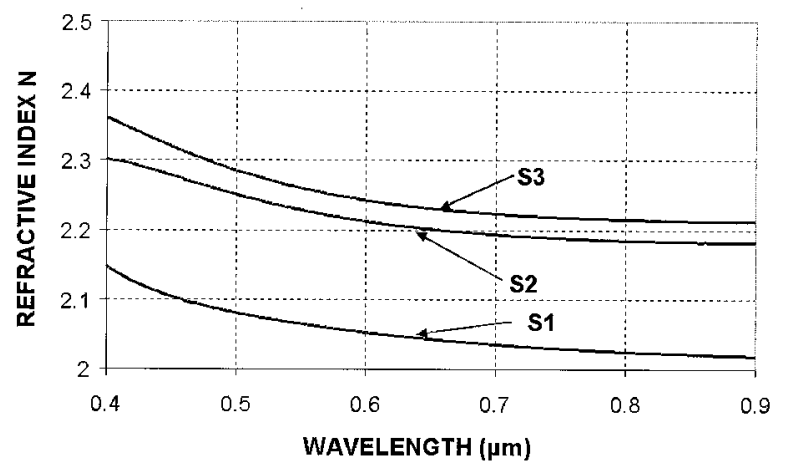

Fig. 3. Calculated real parts of the refractive indices $N$ for $\mathrm{S} 1, \mathrm{~S} 2$, and $\mathrm{S} 3$ as a function of the wavelength.

$\mathrm{Ta}_{2} \mathrm{O}_{5}$ is improved. If we take the scattering level of S1 as a reference, the average level of S2's; scattered light is double, and the level of S3's scattered light is approximately 50 times higher. Roughness at the two interfaces (air- $\left.\mathrm{Ta}_{2} \mathrm{O}_{5}\right)$ and $\left(\mathrm{Ta}_{2} \mathrm{O}_{5}\right.$-substrate) and also the compactness of the film are probably the parameters influencing the amount of scattered light. Further research needs to be done to clarify the relation between film microstructure and light scattering. Finally, these losses should be decreased with more compact layers. A more energetic deposition process such as ion assistance could be a solution, provided that the microstructure remains compatible with a piezoelectric effect.

\section{Nonoptical Characterizations and the Expected Piezoelectric Effect}

Nonoptical characterizations able to predict the piezoelectric displacement of the film include x-ray diffraction (XRD) diagrams and scanning electron microscopy (SEM) images. XRD analysis is performed on a Philip's X'Pert diffractometer. The initial information given is the crystal structure of the $\mathrm{Ta}_{2} \mathrm{O}_{5}$ particles used in the crucible for evaporation. The Merck tantalum pentoxide tablets, whose measured XRD spectrum is given on Fig. 5, are identified as belonging to the orthorhombic class. ${ }^{15}$ The lattice

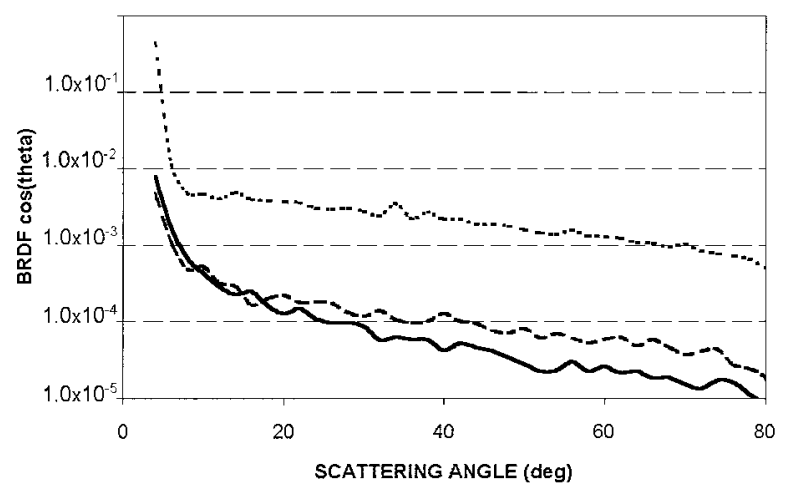

Fig. 4. Bidirectional reflectance distribution function (BRDF) as a function of the measurement angle. Samples are illuminated under normal incidence. 


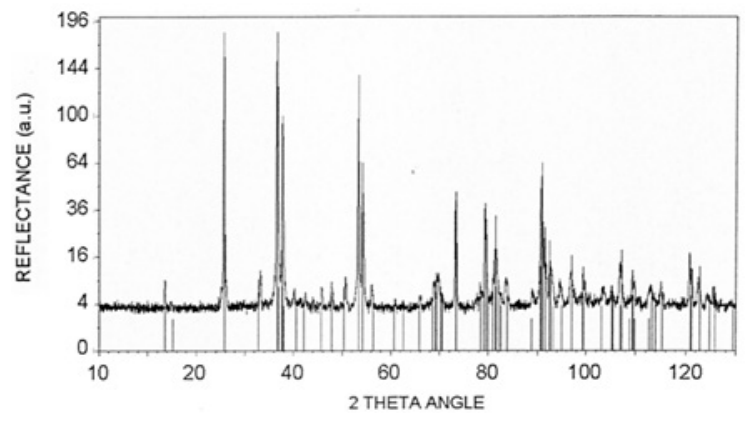

Fig. 5. X-ray diffraction spectra of $\mathrm{Ta}_{2} \mathrm{O}_{5}$ powder. Theta is the angle between the incident light and the sample. 2theta is the angle between the incident light and the reflected beam in the incident plane. The theoretical diffraction efficiency is also shown.

parameters are $a=0.6198 \mathrm{~nm}, b=4.029 \mathrm{~nm}, c=$ $0.3888 \mathrm{~nm}$, and $\alpha=\beta=\gamma=90^{\circ}$.

$\mathrm{XRD}$ and SEM analyses provide complementary information about the degree of crystallinity, the average size of crystallites, and the overall texture of the film. We show results of a set of four samples of $\mathrm{Ta}_{2} \mathrm{O}_{5}$ thin films coated on fused-silica substrates. The mechanical thickness of all samples is approximately $375 \mathrm{~nm}$. The substrate temperature during the deposition process was different for each sample.

Sample S4 (reference sample), coated at a $300{ }^{\circ} \mathrm{C}$ substrate temperature, is revealed to be totally amorphous. No diffraction peak is visible on the XRD spectrum. [Fig. 6(a)]. The shape of the spectrum is characteristic of the substrate atoms' disposition (here fused silica).

Sample $\mathrm{S} 5$ is a $\mathrm{Ta}_{2} \mathrm{O}_{5}$ thin film coated on a $470{ }^{\circ} \mathrm{C}$ heated substrate. Its XRD spectrum [Fig. 6(b)] exhibits several diffraction peaks at particular angles, defined by $\mathrm{Ta}_{2} \mathrm{O}_{5}$ crystal parameters. An orthorhombic crystal system is also identified. All peaks have different intensities, but no peak is really prominent. This indicates that the coating is polycrystalline with a random grain orientation.

The temperature of the substrate for sample $\mathrm{S} 6$ is approximately $620^{\circ} \mathrm{C}$ during the deposition process. In this case, increasing the adatoms' energy permits them to re-arrange themselves in a more stable form, which improves crystallinity. We can see on the XRD spectrum of Fig. 6(c) that the intensity of the peak located at $2 \theta=28.6^{\circ}$ has become much more important than the others. This means that the proportion of ( $\left.\begin{array}{lll}1 & 11 & 0\end{array}\right)$ planes parallel to the substrate surface is higher than others, and therefore the layer exhibits a textured crystallized structure. We might be able to measure a small piezoelectric displacement for this sample, but it would be many times below the displacement of the same bulky layer.

The best-crystallized layer we deposited on a fusedsilica substrate (S7) has been obtained for a high substrate temperature around $650{ }^{\circ} \mathrm{C}$ and for a slow deposition rate of approximately $0.1 \mathrm{~nm} / \mathrm{s}$. We can see on Fig. 6(d) that only one diffraction peak $(2 \theta=$ $28.6^{\circ}$ ) is visible. This is characteristic of a welltextured film structure with a general orientation in the $\left(\begin{array}{lll}1 & 11 & 0\end{array}\right)$ plane parallel to the substrate surface. S7 should present a noticeable piezoelectric effect.

In addition to performing XRD analysis, we show SEM images of samples S4, S5, S6, and S7 achieved with an Oxford Instruments high-resolution scanning electron microscope on Fig. 7.

The SEM images give information about the film structure in agreement with the conclusion stated above. S4 is totally amorphous, crystallites of S5
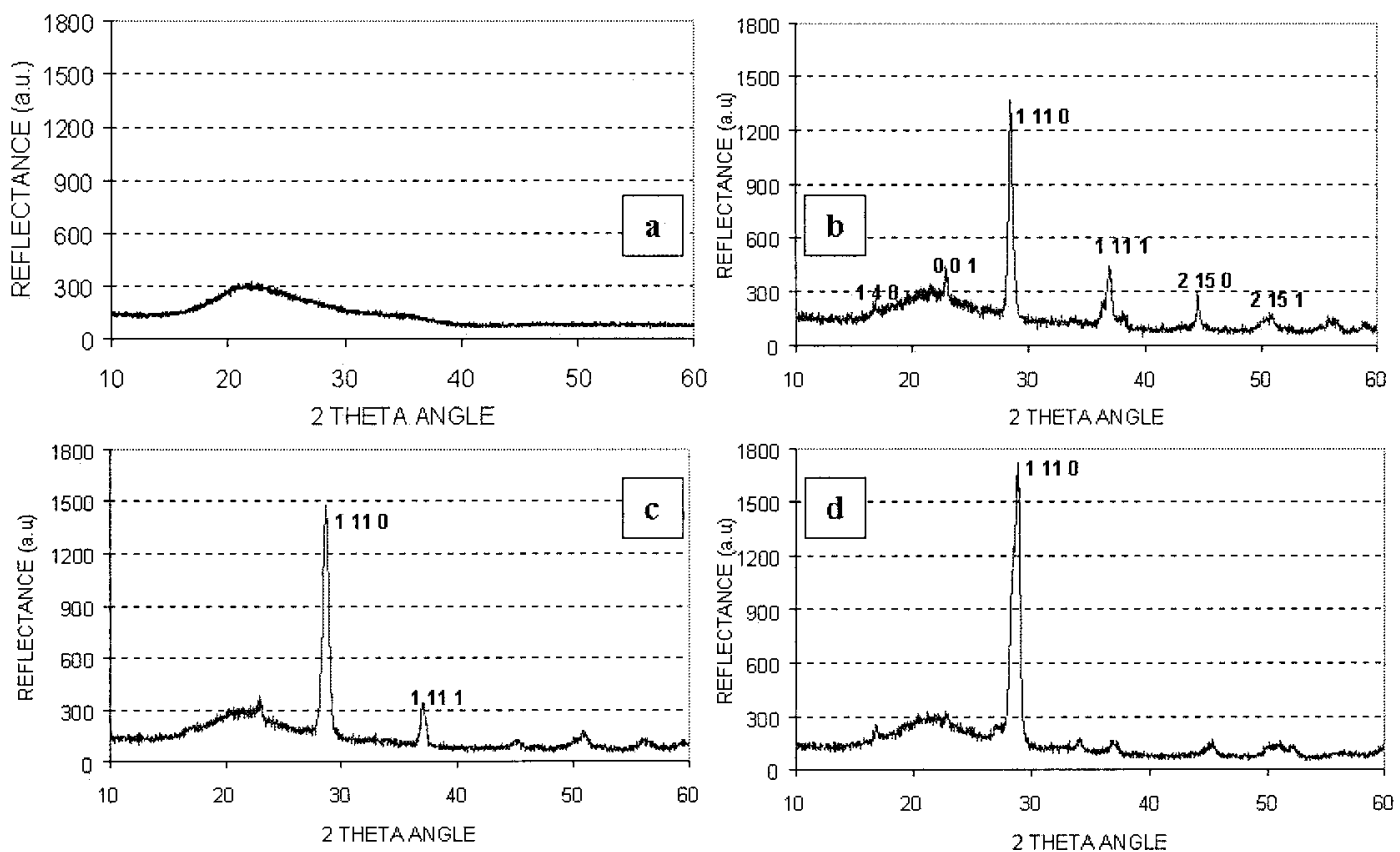

Fig. 6. X-ray diffraction spectra of samples: (a) S4, (b) S5, (c) S6, and (d) S7. 


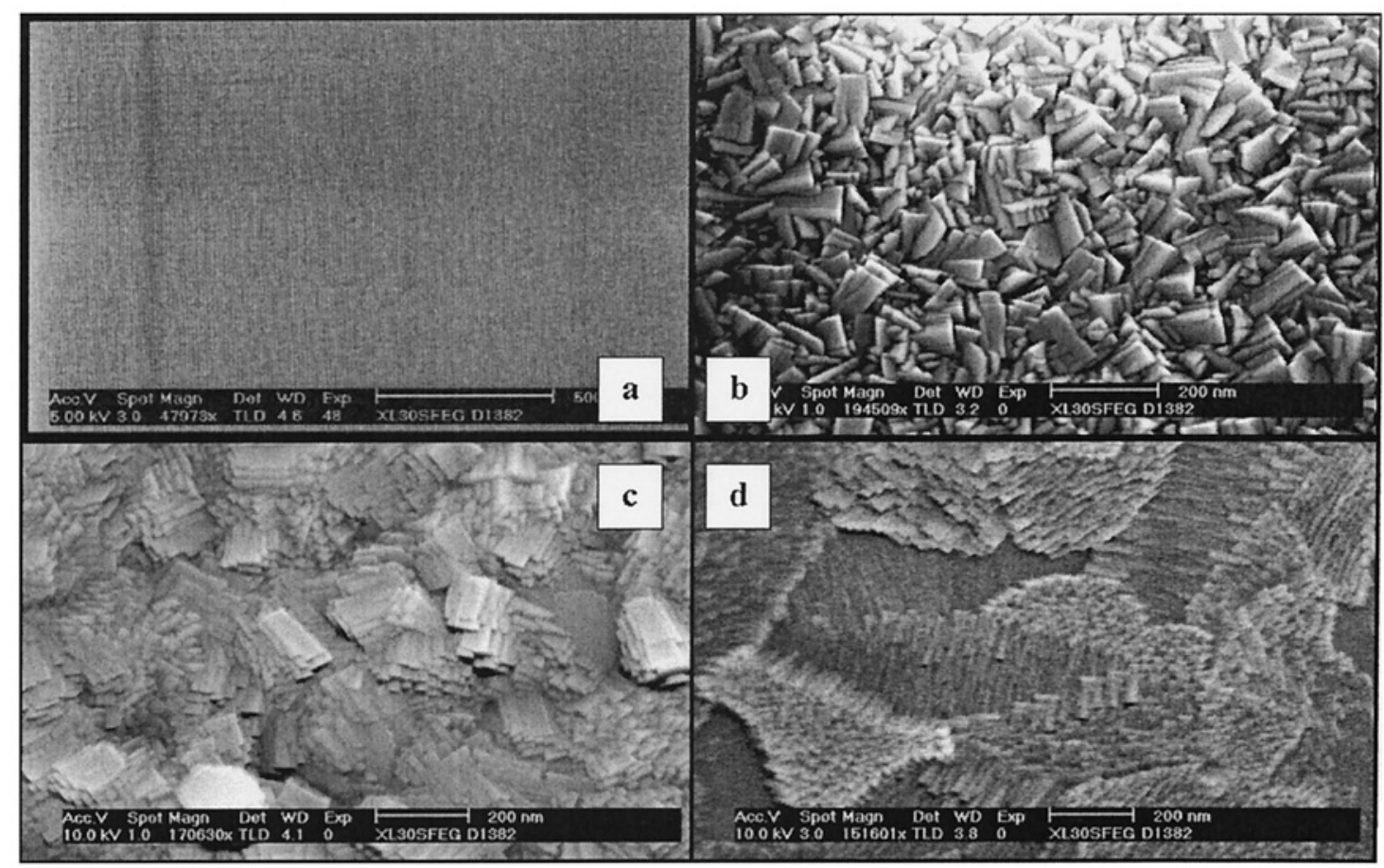

Fig. 7. Scanning electron microscopy of samples: (a) S4, (b) S5, (c) S6, and (d) S7.

are randomly oriented, and S6 and especially S7 have a general orientation. We can also measure the mean grain size. For crystallized layers, the average form of crystallites, measured on sample S6, is a parallelepipedal $100 \mathrm{~nm}$ long, $50 \mathrm{~nm}$ in width, and 10 $\mathrm{nm}$ in height. Unfortunately, pollution from the heater on the rear sides of the substrates did not permit us to perform optical characterizations on samples S5 to S7.

\section{Interferometric Measurement of Piezoelectric Displacement}

Among the different means available to measure piezoelectric coefficients or piezoelectric displacements under an applied electric field, we can find interferometric measurement setups that give results as accurate as $0.1 \mathrm{pm} .{ }^{16-18}$ At this time, we note that we expect dimension changes for our thin films of approximately $1 \mathrm{pm}$. We have chosen to implement a fiber interferometer that, as we will discuss in the following, is easy to use in terms of precise adjustments.

The setup we use is the extrinsic Fabry-Perot interferometer, previously reported in other papers. ${ }^{17,19}$ The general overview, of the instrument can be seen on Fig. 8. It is basically composed of a Y-monomode fiber coupler that performs the interferometer function. The incoming light wave emitted by a tunable laser is coupled into the entrance fiber. At the end of the exit fiber (right side of the schematic), part of the light (approximately 4\%) is reflected backward because of the refractive-index difference between the fiber core and the air; this wave is taken as the reference wave. The other part of the light is coupled out of the fiber, and the unique mode that was propagating through the fiber diverges. When a surface is facing the fiber exit, the diverging wave is reflected on this surface. Then a small part (defined by a coefficient $\eta$ ) of this coupled-out wave can be again coupled into the same exit fiber (measurement wave). If the optical path difference between what we called the reference wave and the measurement wave is below the laser coherence length, and because we use a monomode fiber, those two waves can interfere inside the fiber. We use the last port of the coupler component, where $50 \%$ of the interfering light is transmitted, to detect the interference pattern.

As in any interferometer, the output intensity is

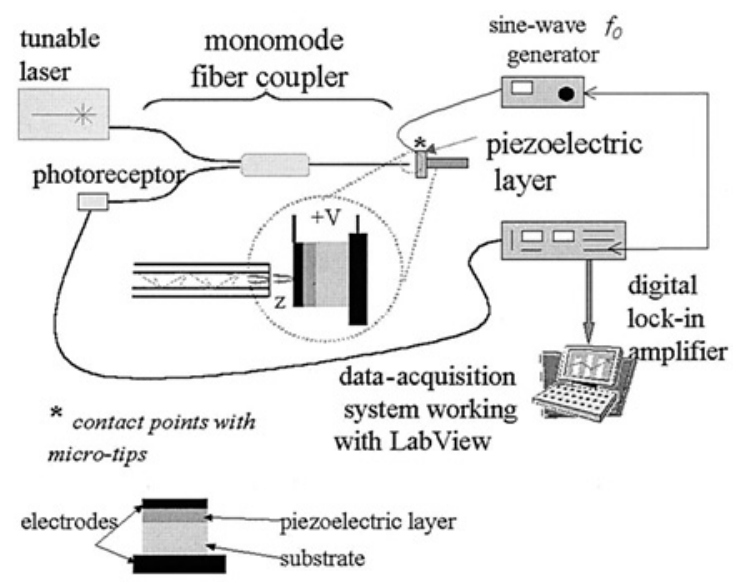

Fig. 8. Extrinsic Fabry-Perot interferometer experimental setup. The photoreceptor measures the interference fringes between the sample and the glass-air interface of the fiber. 


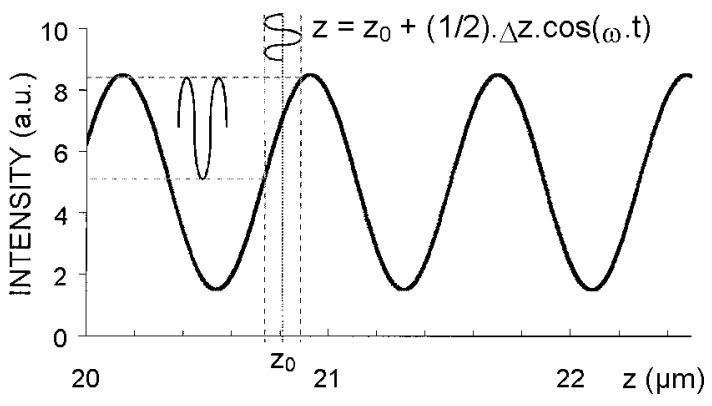

Fig. 9. Theoretical intensity detected by a photoreceptor as a function of the distance $z$ between the fiber exit and the sample surface.

the square modulus of the sum of the two waves' complex amplitudes. It can be expressed in Eq. (2) as

$$
I=I_{0}[1+m \cos (\phi)],
$$

where $m$ is the visibility of the interference pattern and $\phi$ is the phase difference between the waves given by

$$
\phi=4 \pi z / \lambda .
$$

We focus on the fact that $\phi$ depends both on the wavelength $\lambda$ and on the distance $z$ between the output of the fiber and the sample surface. Without giving further details, we note that $m$ can be calculated as a function of $\eta$. As can be seen on Fig. 9, intensity on the photoreceptor changes when the distance between the fiber output and the sample varies (thick solid curve). Let us suppose that we apply an oscillating electric field $E$ (oscillating at pulsation $\omega$ ) to our piezoelectric sample characterized by its piezoelectric coefficient $d$. This field involves an oscillating displacement whose amplitude is given by $\Delta z_{\omega}=$ $d(E)$. Thus we measure the intensity variations $\Delta I_{\omega}$ with a lock-in amplifier at pulsation $\omega$. We can calculate $\Delta I_{\omega}$ by differentiating Eq. (2). This leads to

$$
\Delta I_{\omega}=-I_{0} m \sin (\phi) \frac{4 \pi}{\lambda} \Delta z_{\omega} .
$$

The visibility of piezoelectric-induced intensity variations on the photoreceptor is affected by $\sin (\phi)$. We use the wavelength tunability of our laser to set $\sin (\phi)=1$ (peak values on Fig. 10). Thus, if we measure first the value of interferometric visibility $m$, we can deduce $\Delta z_{\omega}$.

We have performed calibration measurement on a piezoelectric lead zirconate titanate ceramics transducer and measured displacements as small as a few tenths of a picometer. Below this limit, the signal is overwhelmed by noise. This noise originates both from the intensity noise of the laser and from the mechanical vibrations.

To characterize the samples described in Section 5, we deposited an electrode metallic coating on the top of each $\mathrm{Ta}_{2} \mathrm{O}_{5}$ layer. The rear face of the substrate is laid down onto a metallic plate, and then a high volt-

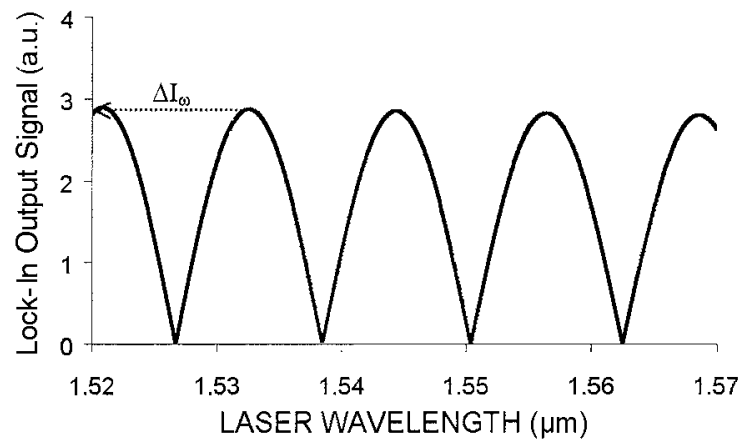

Fig. 10. Principle of the measurement of a small $f_{0}$ displacement from the intensity detected for two working points.

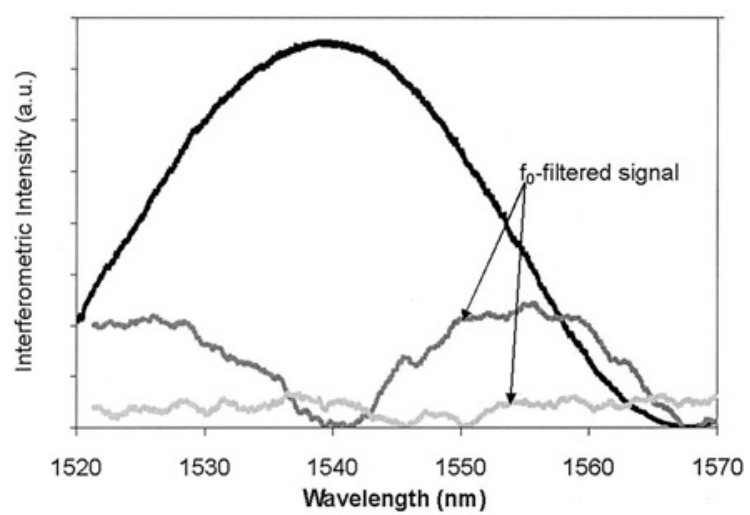

Fig. 11. Interferometric intensity measured as a function of the incident wavelength, the distance between the fiber and the sample being constant (black curve). Under a $400-V$ voltage at $f_{0}=$ $10^{5} \mathrm{~Hz}$, we show the $f_{0}$-filtered signal for sample 7 (dark gray curve) and for sample 4 (light gray curve).

age $(400 \mathrm{~V})$ is applied between the two electrodes at frequency $f_{0}=\omega / 2 \pi=10^{5} \mathrm{~Hz}$. Given the thickness of the substrate $(2 \mathrm{~mm})$, the electric field applied on the sample is $2 \mathrm{kV} / \mathrm{cm}$, much less than the breakdown electric field. The voltage between the two sides of the $\mathrm{Ta}_{2} \mathrm{O}_{5}$ layer (375-nm thickness) is $75 \mathrm{mV}$, and we measured a displacement of $1 \mathrm{pm}$ for S7. The measurement curve (having the same form as the simulated curve given on Fig. 10, which is a proof for the interferometric origin of the signal) after processing for conversion into displacement units is shown on Fig. 11. This value corresponds to a variation of thickness approximately $13 \mathrm{pm} / \mathrm{V}$ for a sandwiched layer between two electrodes, much less than the possible $200 \mathrm{pm} / \mathrm{V}$ for a single-crystalline $\mathrm{Ta}_{2} \mathrm{O}_{5}$ structure. The validity of the procedure is proven by repetition of the same protocol for $\mathrm{S} 4$ (amorphous layer), in which no $f_{0}$ frequency displacement is detected (see Fig. 11).

\section{Conclusion}

Changing the coating deposition parameters and especially heating the substrate temperature to as high as $650^{\circ} \mathrm{C}$ during deposition enables us to obtain crystallized layers. We showed that $\mathrm{Ta}_{2} \mathrm{O}_{5}$ thin films coated on an amorphous substrate heated above 
$620^{\circ} \mathrm{C}$ can present a preferred orientation compatible with a piezoelectric displacement on the growth axis. The greatest thickness variation we measured is approximately $13 \mathrm{pm} / \mathrm{V}$.

The study of optical properties for hightemperature coated or annealed $\mathrm{Ta}_{2} \mathrm{O}_{5}$ layers demonstrates not only a high refractive index (approximately $\mathrm{N}=2.25$ at a wavelength of $600 \mathrm{~nm}$ ) but also an increase in scattered light. These scattered losses depend on the size of the crystallites. Smaller grains or more compact layers with an assisted deposition process should improve the optical quality of layers. By optimizing deposition parameters, we should increase the piezoelectric effect of the layers and decrease the scattered light. The insertion of such layers into Fabry-Perot cavities with transparent conductive electrodes could be a way to tune the transmitted wavelengths for telecommunication applications. ${ }^{1}$

We thank Carole Deumie for scattering measurements and for useful discussions.

This research is supported by Highwave Optical Technologies Marseille, Z.I. St Mitre, avenue de la Roche Fourcade, 13400 Aubagne, France, and by Le Conseil Régional Provence-Alpes-Côte-d' Azur.

\section{References}

1. M. Lequime, R. Parmentier, F. Lemarchand, and C. Amra, "Toward tunable thin-film filters for WDM applications," Appl. Opt. 41, xxxx-xxxx (2002)

2. W. P. Mason, Piezoelectric Crystals and Their Application to Ultrasonics, 6th ed. (Van Nostrand, Princeton, N. J. 1964), pp. $40-46$.

3. J. G. E. Gardeniers, Z. M. Rittersma, and G. J. Burger, "Prefered orientation and piezoelectricity in sputtered $\mathrm{ZnO}$ films," J. Appl. Phys. 83, 7844-7854 (1998).

4. A. Yariv and P. Yeh, Optical Waves in Crystals (Wiley, New York, 1984), p. 233.

5. C. Chaneliere, J. L. Autran, R. A. B. Devine, and B. Balland, "Tantalum pentoxide thin films for advanced dielectric applications," Mater. Sci. Eng. 22, 269-322 (1998).

6. D. R. Lide, Handbook of Chemistry and Physics, 76th ed. (CRC Press, Boca Raton, Fla., (1995).
7. B. R. Jooste and H. J. Viljoen, "A study of piezoelectric orthorhombic Ta2O5," J. Mater. Res. 13, 475-482 (1998).

8. H. K. Pulker and K. H. Guenther, "Reactive physical vapor deposition processes," in Thin Films for Optical Systems, F. R. Flory, ed. (Marcel Dekker, New York, 1995), pp. 91-115.

9. S. Boughaba, G. I. Sproule, J. P. McCaffrey, M. Islam, and M. J. Graham, "Synthesis of tantalum pentoxide films by pulsed laser deposition: material characterization and scaleup," Thin Solid Films 358, 104-113 (2000).

10. J. Y. Zhang, Q. Fang, and I. W. Boyd, "Growth of tantalum pentoxide film by pulsed laser deposition," Appl. Surf. Sci. 138-139, 320-324 (1999).

11. T. Dimitrova, K. Arshak, and K. Atanassova, "Crystallization effects in oxygen annealed Ta2O5 thin films on Si," Thin Solid Films 381, 31-38 (2001).

12. B. A. Movchan and A. V. Demchishin, "Investigations of the structure and properties of thick $\mathrm{Ni}, \mathrm{Ti}, \mathrm{W}, \mathrm{Al} 2 \mathrm{O} 3$ and $\mathrm{ZrO} 2$ vacuum condensates," Fiz. Met. Metalloved. 28, 653-660 (1969).

13. J. P. Borgogno, B. Lazarides, and P. Roche, "An improved method for the determination of the extinction coefficient of thin film materials," Thin Solid Films 102, 209-220 (1983).

14. C. Deumie, R. Richier, P. Dumas, and C. Amra, "Multiscale roughness in optical multilayers: atomic force microscopy and light scattering," Appl. Opt. 35, 5583-5594 (1996).

15. International Centre for Diffraction Data, "Joint Committee on Powder Diffraction Standards (JCPDS) Card No. 25-0922" (ICDD, Newton Square, Pa. (1996).

16. L. Burianová, M. Sule, and M. Prokopová, "Determination of the piezoelectric coefficients $d_{i j}$ of PZT ceramics and composites by laser interferometry,” J. Eur. Ceram. Soc. 21, 13971390 (2001).

17. M. Schmidt, B. Werther, N. Fuerstenau, M. Mathias, and T. Melz, "Fiber-optic extrinsic Fabry-Perot interferometer strain sensor with $<50 \mathrm{pm}$ displacement resolution using threewavelength digital phase demodulation," Opt. Express 8, 475480 (2001).

18. N. Felix, D. Certon, F. Patat, and M. Lethiecq, "Piezoelectric materials, ultrasound transducers and arrays characterization by laser interferometry," e-Journal Non-Destr. Test. Ultrasonics 5 (2000), www.ndt.net/article/v05n09/felix/felix.htm.

19. M. Lequime and J. J. Guerin, "Large OPD extrinsic FabryPerot interferometers using thermally expanded core fiber," in European Workshop on Optical Fibre Sensors, B. Culshaw and J. D. Jones, eds., Proc. SPIE 3483, pp. 179-183 (1998). 